prosthesis. Although the results of the original paper from our institution may be viewed from a different perspective and appear to satisfy different results, the fact remains that the altered design of the Björk-Shiley valve did not reduce or eliminate the risk of valve thrombosis. More spherical than convexoconcave discs were affected by thrombosis; however, the mean time to valve thrombosis was 3.7 years. The follow-up of the convexo-concave cohort was not sufficiently long to state that the risk was absent. The presence of two of ten aortic thromboses confirms the possibility. The development of thrombosis in any location would be cause for concern. Our data demonstrated that thrombosis did occur and appears time related. The absence of a mitral occurrence in our review with the convexo-concave prosthesis is not a valid testimony to correction of this complication of thrombosis, as time will verify or negate its occurrence.

We do not recommend elective replacement of the convexoconcave prosthesis alone. If the need for repeat cardiac surgery for other cardiac disease arises, elective replacement should be considered, and if the combined procedure does not increase the operative risk significantly, we would support the explantation of the convexo-concave prosthesis.

There is no U.S. experience with the Monostrut valve, but I would surmise from Dr. Lindblom's comments that strut fracture and thrombosis have been avoided in his experience. We are attentive to any improvements that will minimize or eliminate risks to our patients. It is difficult to predict when or whether this prosthesis will reach the U.S. market.

Thomas A. Orszulak, MD Thoracic and Cardiovascular Surgery Rochester, MN 55905

\section{Cellular kinetics of posttransfusion graft-versus-host disease after heart operations}

\section{To the Editor:}

Postoperative erythroderma evidenced by high fever, erythroderma, liver dysfunction, diarrhea, and pancytopenia has been understood as a graft-versus-host disease (GVHD) caused by blood transfusion. ${ }^{1-3}$ This devastating disease typically occurs when the donor's human leukocyte antigen (HLA) haplotypes are homozygous for one of the patient's HLA haplotypes, because graft-versus-host reaction against the patient's major (and minor) histocompatibility antigens is much stronger than host-versus-graft reaction against the donor's minor histocompatibility antigens in this case. ${ }^{4,5}$ In practice, the fresher and more closely related the transfused blood is, the greater is the risk of GVHD. ${ }^{6-8}$ Moreover, not only immunocompromised hosts but also postcardiotomy patients seem to be vulnerable to this disease. ${ }^{9}$ Its prevalence after heart operations in Japan has been reported to be $0.15 \%$. The mortality rate is as high as $90 \%$. ${ }^{9}$

We present here three cases of GVHD occurring after heart operations and the transfusion of fresh or preserved blood. In one of these cases, extensive analysis of the cellular kinetics of posttransfusion GVHD after a heart operation (including HLA typing of the patient, his family and the blood donors) was performed.

A 67-year-old Japanese man (patient 1) with rheumatic mitral stenosis and regurgitation was referred to Matsuyama Red Cross Hospital. Blood test results were all within the normal limits. Mitral valve replacement was performed in Septem- ber 1991. For priming of the cardiopulmonary bypass (CPB) circuit, $260 \mathrm{gm} 5$-day preserved concentrated red blood çells (CRBCs) from donor 1 and $130 \mathrm{gm} \mathrm{15-day} \mathrm{preserved} \mathrm{CRBCs}$ from donor 2 were used. Soon after the operation, an additional $260 \mathrm{gm}$ 5-day preserved CRBCs from donor 3 was given. All three blood donors were unrelated to the patient. The patient's postoperative course was uneventful until spiking fever started on postoperative day (POD) 10. On POD 14, a mild elevation of liver enzyme activities (such as aspartate aminotransferase, alanine aminotransferase, and lactic dehydrogenase) and a rash on the face and neck were observed. The rash gradually spread over the entire body surface, culminating in an appearance similar to that of a second-degree burn by POD 19. On POD 17, watery (later bloody) diarrhea associated with redness, swelling, and erosion in the lips and anus began. Delirium was observed from POD 16 through POD 19. The patient entered into a state of shock on POD 19 and died on POD 20. Permission for autopsy was refused, but the histologic appearance of the skin at death was fully compatible with GVHD. ${ }^{10}$ The bone marrow was not examined.

The hemoglobin level and red blood cell count were relatively constant throughout the postoperative course (Fig. 1). The decreased platelet count caused by CPB had returned to its normal level by POD 10 but decreased again after POD 14. The white blood cell count, which increased after the operation, appeared to have returned to normal by POD 10; thereafter, however, it continuously decreased, to 3100 cells $/ \mathrm{mm}^{3}$ on POD 18 and to 500 cells $/ \mathrm{mm}^{3}$ on PODs 19 and 20 . The differential count of the white blood cells was dramatically and suddenly changed from granulocyte dominance $(>80 \%)$ to lymphocyte dominance $(>96 \%)$ on POD 18 . The absolute number of lymphocytes decreased from 1403 cells $/ \mathrm{mm}^{3}$ before operation to 411 cells $/ \mathrm{mm}^{3}$ immediately after operation; it then showed a plateau at about 1000 cells $/ \mathrm{mm}^{3}$ from PODs 7 through 14 , followed by a further rapid drop to 93 cells $/ \mathrm{mm}^{3}$ on POD 17 . The lymphocyte count did, however, increase again to about 500 cells $/ \mathrm{mm}^{3}$ after POD 18 .

Shortly before the patient's death, blood was drawn to examine the HLA phenotypes and lymphocyte subpopulations. Moreover, the patient's wife, his three children, and the three unrelated blood donors were tested for their HLA phenotypes. Although the expected HLA haplotypes of the patient were A24, Bw52, C-, DR2, DQw1/A-, B35, Cw9, DR4.1, DQw4 (a/b, Table I), his HLA haplotypes just before his death were found to be a/a-exactly the same as the HLA haplotype of donor 3 (a 23-year-old man). The frequency of haplotype a in Ehime Prefecture, Japan, has been reported to be 0.0593. ${ }^{11}$ If the patient had been a mixed chimera, the patient's original lymphocytes, bearing haplotype b-encoded antigens, would have been detected. From a quantitative analysis of the HLAtyping scores (Table I), however, Cw9, DR4. 1, and DQw4 were scored into 1 and B35 was scored into 2, suggesting that the existence of host-type lymphocytes was negligible (Table I). From a flow-cytometric analysis of the patient's blood, $\mathrm{T}$ cells $\left(\mathrm{CD}^{+}\right)$accounted for $84 \%$ of the mononuclear cells, whereas $\mathrm{B}$ cells $\left(\mathrm{CD} 19^{+}\right)$represented $0 \%$. Among the donor-originated $\mathrm{T}$ cells, $10 \%$ were $\mathrm{CD}^{+}$and $79 \%$ were $\mathrm{CD} 8^{+}$(Fig. 1). This patient was the first to have posttransfusion GVHD among 400 heart operations at Matsuyama Red Cross Hospital from 1983 through 1991. 


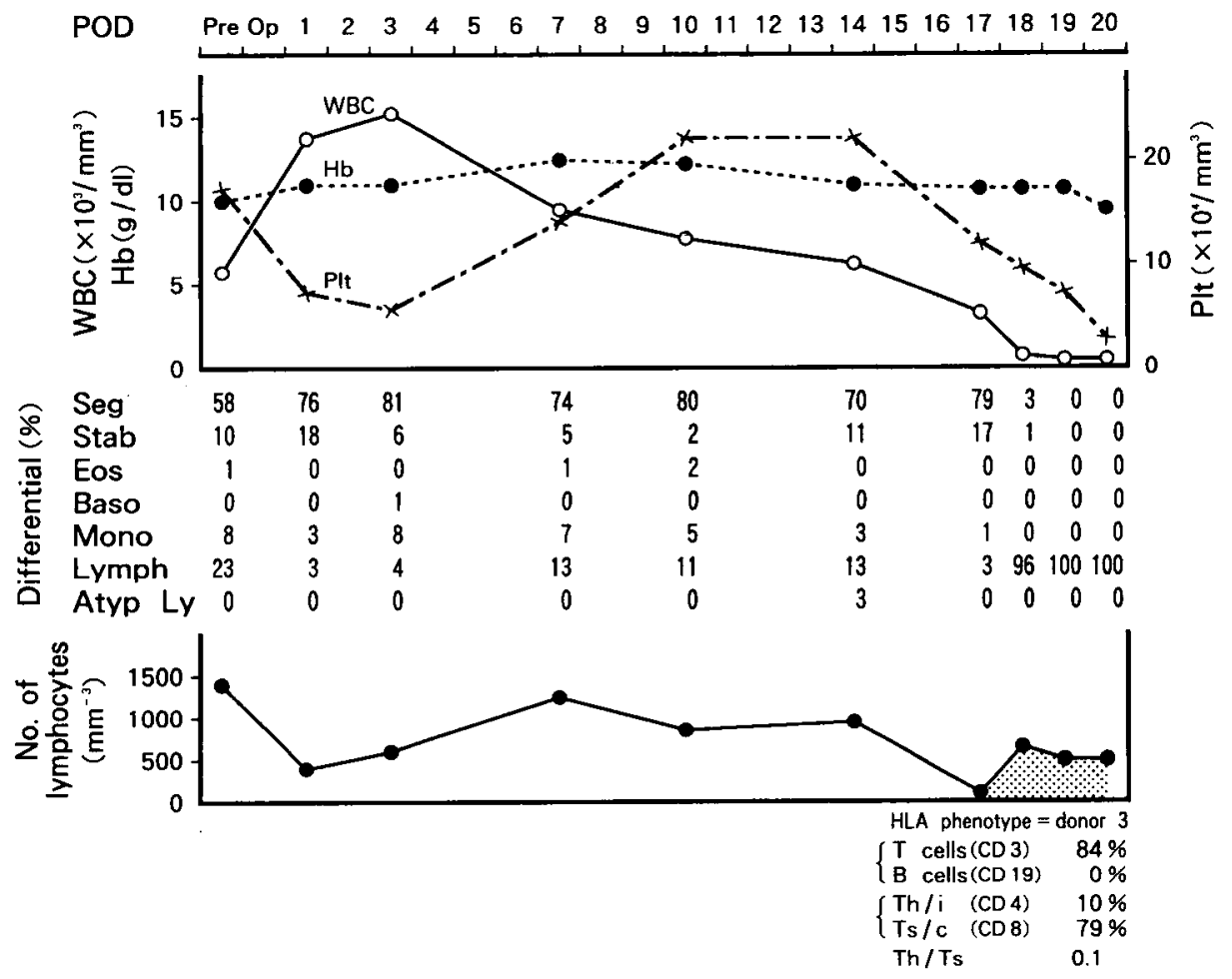

Fig. 1. Cellular kinetics of posttransfusion GVHD in patient 1. WBC, White blood cells; $H b$, hemoglobin; Plt, platelets; Seg, segmented neutrophils; Eos, eosinophils; Baso, basocytes; Mono, monocytes; Lymph, lymphocytes; Atyp L $y$, atypical lymphocytes; Th/i, helper/inducer T cells; $T s / c$, Suppressor/cytotoxic T cells. Dotted area corresponds to reconstitution of lymphocytes with donor haplotype.

Among 2660 patients who underwent heart operations from 1975 through 1991 in Kyushu University Hospital, two patients, both operated on in 1985, were found to have posttransfusion GVHD. Patient 2 was a 59-year-old man with ischemic heart disease in whom coronary artery bypass grafting was performed. Patient 3 was a 65 -year-old man with rheumatic heart disease in whom double-valve replacement and tricuspid annuloplasty were performed. In both cases, fresh blood transfusion from related or unrelated donors was performed. The postoperative clinical courses and cellular kinetics of these two patients were remarkably similar to those of patient 1 . The lymphocyte dip associated with the differential change from granulocyte dominance to lymphocyte dominance was observed on POD 17 in patient 2 and on POD 20 in patient 3. Predeath diagnosis of posttransfusion GVHD was made in patient 3 by skin biopsy and bone marrow tap. HLA typing was not performed in either patient 2 or 3 .

As reported previously, $4,5,12$ a patient with ongoing GVHD could be either partially or completely chimeric. From the quantitative analysis of the HLA-typing scores, patient 1 appeared to be completely or highly chimeric on POD 20. The lymphocyte dip associated with the differential change from granulocyte dominance to lymphocyte dominance occurred from POD 17 to 20 in all three patients. This dip in the absolute lymphocyte count seems to imply a turning point in the takeover by donor-originated lymphocytes. Ito and colleagues ${ }^{3}$ also reported that a change of HLA phenotype occurred on POD 17 in a patient with esophageal cancer who underwent operation and transfusion with fresh blood. All three patients in our study showed rapid deterioration in condition after the lymphocyte dip.

Methylprednisolone was used for all of our patients, but none was able to survive. Thaler and colleagues ${ }^{8}$ reported that antithymocyte globulin was effective in prolonging the life of a patient with posttransfusion GVHD. OKT3 may not be able to fully reverse GVHD, ${ }^{13}$ but as an antibody to $T$ cells it seems so far to be one of the safest and most effective drugs in treating posttransfusion GVHD; however, we could not use OKT3 because of its test stage in Japan. As a result of our extensive experimental studies on cyclophosphamide-induced tolerance, ${ }^{14,16}$ the use of cyclophosphamide in patient 1 was discussed but dismissed because of the devastated state of the patient. Injections of cyclophosphamide at a dose range of 20 to $100 \mathrm{mg} / \mathrm{kg}$, however, seem to be effective in treating animals with posttransfusion GVHD (Fujiwara M, personal communication ). In our patients, clinical status worsened day by day after the skin rash started and shift by shift after the lymphocyte dip was observed. Aggressive treatment should therefore be started as soon as possible once the lymphocyte dip has been confirmed. Granulocyte colony-stimulating factor ${ }^{17}$ was not effective in patient 1. Isolation in a laminar-flow room is recommended for such immunocompromised patients. ${ }^{18}$ Because of difficulty in 
Volume 108, Number 1

Table I. HLA phenotypes and their typing scores

\begin{tabular}{|c|c|c|c|c|c|}
\hline \multirow[b]{2}{*}{ Sample } & \multicolumn{5}{|c|}{ HLA phenotype and typing score at locus } \\
\hline & $A$ & $B$ & $C$ & $D R$ & $D Q$ \\
\hline \multicolumn{6}{|l|}{ Donors } \\
\hline 1 (24-year-old man) & $11(8 \pm 0, n=4)$ & $\begin{array}{l}\text { w46 }(8 \pm 0, n=4) \\
\text { w62 }(8 \pm 0, n=7)\end{array}$ & $\begin{array}{l}\text { w } 4(8 \pm 0, n=4) \\
\text { w11 }(8 \pm 0, n=2)\end{array}$ & NT & NT \\
\hline 2 (47-year-old man) & $\begin{array}{r}2(8 \pm 0, n=4) \\
24(8 \pm 0, n=2)\end{array}$ & $\begin{array}{l}\text { w52 }(8 \pm 0, n=4) \\
\text { w54 }(8 \pm 1, n=6)\end{array}$ & w $1(8 \pm 0, n=6)$ & NT & NT \\
\hline 3 (23-year-old man) & $24(8 \pm 0, n=2)$ & w52 $(8 \pm 0, n=4)$ & - & $2(8 \pm 0, n=5)$ & wl $(8 \pm 0, n=6)$ \\
\hline \multicolumn{6}{|l|}{ Patient } \\
\hline Day 20 & $24(8 \pm 0, n=4)$ & w52 $(8 \pm 0, n=6)$ & - & $2(7 \pm 2, n=4)$ & w1 $(5 \pm 2, n=3)$ \\
\hline Expected & $24(8 \pm 0, n=4)$ & $\begin{array}{r}\text { w52 }(8 \pm 0, n=6) \\
35(2 \pm 1, n=3)\end{array}$ & w9 $(1 \pm 0, n=6)$ & $\begin{array}{r}2(7 \pm 2, n=4) \\
4.1(1 \pm 0, n=8)\end{array}$ & $\begin{array}{l}\text { w1 }(5 \pm 2, n=3) \\
\text { w4 }(1 \pm 0, n=2)\end{array}$ \\
\hline \multicolumn{6}{|l|}{ Relatives } \\
\hline Spouse & $\begin{array}{r}11.1(7 \pm 1, n=3) \\
24(7 \pm 3, n=4)\end{array}$ & $\mathrm{w} 60(7 \pm 2, n=8)$ & $\begin{array}{l}\text { w } 7(3 \pm 1, n=4) \\
\text { w10 }(8 \pm 0, n=3)\end{array}$ & $\begin{array}{r}\text { w8.1 }(4 \pm 3, n=9) \\
9(5 \pm 3, n=6) \\
\text { w52 }(6 \pm 3, n=5) \\
\text { w53 }(7 \pm 3, n=5)\end{array}$ & $\begin{array}{l}\text { w1 }(5 \pm 2, n=6) \\
\text { w3 }(3 \pm 2, n=5)\end{array}$ \\
\hline Son . & $24(8 \pm 0, n=4)$ & $\begin{array}{l}\text { w35 }(7 \pm 2, n=4) \\
\text { w60 }(6 \pm 3, n=8)\end{array}$ & $\begin{array}{l}\text { w } 9(8 \pm 0, n=6) \\
\text { w10 }(8 \pm 0, n=3)\end{array}$ & $\begin{array}{r}4.1(6 \pm 2, n=8) \\
9(7 \pm 3, n=6) \\
\text { w53 }(8 \pm 1, n=5)\end{array}$ & $\begin{array}{l}\text { w3 }(6 \pm 2, n=5) \\
\text { w4 }(6 \pm 0, n=2)\end{array}$ \\
\hline Daughter 1 & $24(8 \pm 0, n=4)$ & $\begin{array}{r}35(8 \pm 1, n=4) \\
\text { w60 (7 }( \pm 1, n=8)\end{array}$ & $\begin{array}{l}\text { w9 }(8 \pm 0, n=6) \\
\text { w10 }(8 \pm 0, n=3)\end{array}$ & NT & NT \\
\hline Daughter 2 & $\begin{array}{r}11.1(8 \pm 0, n=3) \\
24(8 \pm 0, n=4)\end{array}$ & $\begin{array}{l}\text { w52 }(8 \pm 0, n=6) \\
\text { w60 }(7 \pm 3, n=8)\end{array}$ & w $7(5 \pm 2, n=4)$ & $\begin{array}{r}2(8 \pm 0, n=5) \\
\text { w8.1 }(4 \pm 3, n=9) \\
w 52(4 \pm 2, n=5)\end{array}$ & wl $(6 \pm 2, n=6)$ \\
\hline
\end{tabular}

Typing was carried out by the National Institutes of Health microlymphocytotoxicity test method. Typing score \pm standard deviation is shown in parenthesis with the number $(n)$ of antisera used. The percentage cell death for each score is as follows: $1,0 \%$ to $10 \% ; 2,10 \%$ to $20 \% ; 4,20 \%$ to $40 \% ; 6,40 \%$ to $80 \%$; and $8,80 \%$ to $100 \%$. Negative controls are designated as 1 , positive controls as 8 . Probable HLA haplotypes of the family, including deduced HLA haplotypes of patient 1, are as follows: patient 1, a/b; spouse, c/d; son, b/c; daughter 1, b/c; and daughter 2, a/d. At his death on day 20 , actual HLA haplotypes of patient 1 were a/a, identical to that of donor 3. Haplotypes are as follows: $a$, A24-Bw52-CBL-DR2-DQw 1; $b$, ABL-B35-Cw9-DR4. 1-DQw4; $c$, A24-Bw60-Cw10DR9-DRw53-DQw3; and d. A 11.1-Bw60-Cw7-DRw8.1-DRw52-DQw1. NT, Not tested.

treating or even diagnosing posttransfusion GVHD, prevention of the disease by autologous blood transfusion, irradiation of allogeneic blood ${ }^{7}$ (not only for related and fresh blood but also for unrelated and preserved blood), leukocyte filtration, ${ }^{19}$ or ultraviolet irradiation ${ }^{20}$ is of the utmost importance.

In case 1, a donor's HLA haplotypes were homologous for one of the patient's HLA haplotypes. The effector cells related to the pathogenesis of this disease in patient 1 were therefore host $T$ cells reactive against the donor's minor histocompatibility antigens (effector cells of host-versus-graft reaction) and donor $\mathrm{T}$ cells reactive against the host's class I (B35, Cw9), class II (DR4.1, DQw4), and minor histocompatibility antigens (effector cells of graft-versus-host reaction). Determination of the minor histocompatibility antigens of the donor and host partially responsible for the host-versus-graft reaction or graft-versushost reaction is not possible. Despite the 5-day preservation of donor blood in case 1 , the donor $T$ cells consequently overcame the host $T$ cells. As previously reported by Hisatomi and colleagues ${ }^{21} \mathrm{CPB}$ is harmful to $\mathrm{T}$-cell function. The fact that the responsible CRBCs from donor 3 were transfused after (but not before or during) CPB may be of significance. The type (membrane or bubble) of oxygenator, however, seemed irrelevant; both types of oxygenator were used for our three patients.

The rapid reduction in the number of granulocytes (primarily positive for class I antigen), $T$ cells (class I), B cells (classes I and II), monocytes and macrophages (classes I and II), and platelets (class I) in patient 1 after POD 14 was considered to be a type of rejection phenomenon, and is compatible with the fact that red blood cells that were HLA negative were maintained at a relatively constant level. Among the donor-type $\mathrm{T}$ cells in the patient, $10 \%$ were $\mathrm{CD}^{+} \mathrm{T}$ cells reactive primarily against host class II antigens (DR4.1, DQw4) ${ }^{22}$ and $79 \%$ were $\mathrm{CD} 8^{+} \mathrm{T}$ cells reactive primarily against host class I antigens (Bw35, Cw9). ${ }^{22}$ Some of these $\mathrm{CD} 4^{+}$or $\mathrm{CD}^{+} \mathrm{T}$ cells may have been reactive against minor histocompatibility antigens of the host. The so-called $\mathrm{Th} / \mathrm{Ts}$ ratio, which represents the host's immunocompetence, ${ }^{23}$ was 0.13 ; however, this index does not make sense in this particular situation because all the $\mathrm{T}$ cells were of donor origin.

Hisanori Mayumi, $M D$ Kanzi Matsui, $M D$

Kouji Matsuzaki, $M D$

Takayuki Uchida, MD

Keiichi Shinozaki, $M D$

Kouichi Tokunaga, MD

Department of Cardiovascular Surgery Matsuyama Red Cross Hospital Matsuyama, Ehime 790, Japan.

Division of Cardiovascular Surgery Research Institute of Angiocardiology Faculty of Medicine Kyushu University Fukuoka 812, Japan 


\section{REFER EN C ES}

1. Sakakibara T, Juji T. Post-transfusion graft-versus-host disease after open heart surgery [Letter]. Lancet 1986;2: 1099.

2. Arsura EL, Bertelle A, Minkowitz S, Cunningham JN, Grob D. Transfusion-associated graft-vs-host disease in a presumed immunocompetent patient. Arch Intern Med 1988;148:1941-8.

3. Ito $\mathrm{K}$, Yoshida $\mathrm{H}$, Yanagibashi $\mathrm{K}$, et al. Change of HLA phenotype in postoperative erythroderma [Letter]. Lancet 1988;1:413-4.

4. Santos GW, Hess AD, Vogelsang GB. Graft-versus-host reactions and disease. Immunol Rev 1985;88:169-92.

5. Gale RP. Graft-versus-host disease. Immunol Rev 1985; 88:192-214.

6. Von Fliedner V, Higby DJ, Kim U. Graft-versus-host reaction following blood product transfusion. Am J Med 1982;72:951-61.

7. Anderson KC, Weinstein HJ. Transfusion-associated graft-versus-host disease. N Engl J Med 1990;323:315-21.

8. Thaler M, Shamiss A, OrgadS, et al. The role of blood from HLA-homozygous donors in fatal transfusion-associated graft-versus-host disease after open-heart surgery. $\mathrm{N}$ Engl J Med 1989;321:25-8.

9. Juji T, Takahashi K, Shibata Y, et al. Post-transfusion graft-versus-host disease in immunocompetent patients after cardiac surgery in Japan [Letter]. N Engl J Med 1989;321:56.

10. Thomas ED, Storb R, Clift RA, et al. Bone-marrow transplantation (II). N Engl J Med 1975;292:895-902.

11. Sakamoto H, Kinoshita K, Fujiwara I, Takami S, Inouye H. Estimation of an appropriate size of unrelated donor pool for bone marrow transplantation based on current status in Ehime Prefecture [Japanese with English summary]. Ehime Eiken Nenpo 1989;50:31-5.

12. Mayumi H, Himeno K, Tanaka K, Tokuda N, Fan J, Nomoto K. Drug-induced tolerance to allografts in mice. XII. The relationships between tolerance, chimerism, and graft-versus-host disease. Transplantation 1987;44:286-90.

13. Gratama JW, Jansen J, Lipovich RA, Tanke HJ, Goldstein G, Zwaan FE. Treatment of acute graft-versus-host disease with monoclonal antibody OKT3: clinical results and effect on circulating T lymphocytes. Transplantation 1984;38: 469-74.

14. Mayumi H, Good RA. Recent state of cyclophosphamideinduced skin allograft tolerance in mice. Immunobiology 1991;182:323-33.

15. Mayumi H, Good RA. Long-lasting skin allograft tolerance in adult mice induced across fully allogeneic (multimajor $\mathrm{H}-2$ plus multiminor histocompatibility) antigen barriers by a tolerance-inducing method using cyclophosphamide. J Exp Med 1989;169:213-38.

16. Mayumi H, Tokunaga K. Cyclophosphamide-induced chimera-type tolerance to allografts: an overview of druginduced immunological tolerance. Fukuoka Acta Med 1990;81:20-40.

17. Nishimura $Y$, Mayumi $H$, Tomita $Y$, Eto $M$, Maeda $T$,
Nomoto K. Recombinant human granulocyte colony-stimulating factor improves the compromised state of recipient mice without affecting the induction of specific tolerance in the cyclophosphamide-induced tolerance system. J Immunol 1991;146:2639-47.

18. Storb R, Prentice RL, Buckner CD, et al. Graft-versus-host disease and survival in patients with aplastic anaemia treated by marrow grafts from HLA-identical siblings: beneficial effect of a protective environment. $\mathrm{N}$ Engl J Med 1983;308:302-7.

19. Bruisten SM, Tersmette M, Wester MR, et al. Efficiency of white cell filtration and a freeze-thaw procedure for removal of HIV-infected cells from blood. Transfusion 1990;30:833-7.

20. Deeg HJ, Graham TC, Gerhand-Miller L, A ppelbaum FR, Schuening F, Storb R. Prevention of transfusion-induced graft-versus-host disease in dogs by ultraviolet irradiation. Blood 1989;74:2592-5.

21. Hisatomi K, Isomura T, Kawara T, et al. Changes in lymphocyte subsets, mitogen responsiveness, and interleukin-2 production after cardiac operations. J THORAC CARDIOVASC SURG 1989;98:580-91.

22. Springer TA. Adhesion receptors of the immune system. Nature 1990;346:425-34.

23. Bach MA, Bach JF. Imbalance in $T$ cell subsets in human diseases. Int J Immunopharmacol 1981;3:269-73.

\section{Amplified fragment length polymorphism analysis in the evaluation of posttransfusion graft-versus-host disease in a child undergoing extracorporeal membrane oxygenation}

\section{To the Editor:}

Posttransfusion graft-versus-host disease (GVHD) is an infrequent but serious complication of blood transfusion with a mortality rate of $84 \%$ or greater. ${ }^{1}$ Posttransfusion GVHD has been described in preterm and term neonates, in children with congenital immune deficiency, in patients with hematologic and nonhematologic malignant diseases, in both autologous and allogeneic bone marrow transplant recipients, and in an infant undergoing extracorporeal membrane oxygenation (ECMO). ${ }^{2}$ A very high degree of suspicion is required to make the diagnosis of posttransfusion GVHD. Both underreporting and overreporting of posttransfusion GVHD are likely occurring because of the lack of uniform confirmatory criteria in establishing the diagnosis. We report the case of a child presumed to have posttransfusion GVHD on the basis of very strong clinical and histopathologic evidence. Amplified fragment length polymorphism (FLP) analysis was successfully used to rule out what appeared to be a bonafide case of posttransfusion GVHD.

A 21/2-year-old boy with complex congenital heart disease was admitted to Children's Hospital for postoperative ECMO support. He underwent a Blalock-Taussig procedure in early infancy and 3 days before admission underwent a Glenn procedure. His postoperative course was complicated by pneumonia caused by Hemophilus influenza as well as adult respiratory distress syndrome. The patient was supported by ECMO because conventional ventilatory assistance had failed. During 